\title{
Desejo de mundo 34
}

\section{Magda Khouri 35}

\section{Clínica extensa}

Certa vez, em uma das suas apresentações ${ }^{6}$, Fabio Herrmann, ao falar de psicanálise, cultura e sociedade, disse que o mundo não cabe no divã e por ser redondo cairia, pois, como sabemos, rola, além do que o divã está dentro do mundo. Não seria possível fazer essa operação! A psique coletiva não é uma psique individual ampliada e nem o contrário, pois, na concepção do autor, a psique é o sentido humano.

Herrmann procurou recuperar aquilo que constituiu o nosso patrimônio original na obra de Freud: um olhar clínico sobre o mundo. Aí está a raiz do que se denomina clínica extensa.

A direção é pensar a psicanálise como ciência geral da psique, não exclusiva da clínica padrão dos consultórios. Psicanálise aqui entendida, primordialmente, como um método de conhecimento da psique, baseado no fazer interpretativo. $\mathrm{O}$ método "semeador de inconscientes, põe à mostra o que está oculto em qualquer condição humana” 37 .

Como escreveu Hermann: “A técnica não é um desdobramento do setting ou uma receita teórica do que dizer. É a escuta poética, sem melodrama, sem alcaçuz. Deixar que surja o sentido, para lá do alcance estreito da significação, tomá-lo em consideração e aguentar as consequências. Principalmente, não tomar as palavras pelo manual de interpretação, esperando delas um significado literal que não podem ter nas circunstâncias”. 38

\footnotetext{
34 Trabalho apresentado na mesa "Clínica psicanalítica: territórios expandidos no II Simpósio Bienal SBPSP "Fronteiras da Psicanálise: a clínica em movimento" no dia 22 de agosto de 2020.

35 Membro associado da SBPSP, Diretora de Atendimento à Comunidade da SBPSP, organizadora com Bernardo Tanis do livro A trama das cidades.

${ }^{36}$ Conferência realizada por Fabio Herrmann: O poder não corrompe, revela, no dia 7/10/2005, da Jornada de preparação ao XX Congresso Brasileiro de Psicanálise, atividade da diretoria científica da SBPSP.

37 Barone, L.M.(org) (2002). Encontro da Teoria dos Campos. O psicanalista: hoje e amanhã. São Paulo: Casa do psicólogo. P. 291

${ }^{38}$ Hermann, F.(2017). Sobre os fundamentos da psicanálise: quatro cursos e um preâmbulo. São Paulo: Editora Blucher.
} 


\section{A vela e o psicanalista}

Leopold Nosek considera que a escuta psicanalítica está dentro do analista, independente do lugar, e diz ser um dos poucos trabalhos existentes que prescinde da tecnologia, até da elétrica: se o mundo parar e ficar no escuro, bastam duas subjetividades e uma vela!

A imagem criada por Nosek traduz a ideia potente do fazer psicanalítico proposta por André Green sobre o enquadre interno do psicanalista, que é, em última instância, o próprio analista em sua função de guardião do tratamento do paciente.

A experiência da própria análise é fundamental "como propiciadora de uma escuta íntima da própria turbulência pulsional que nos habita, pois aí também reside nossa singularidade e vitalidade" 39 . O que sustentaria a experiência psicanalítica é a possibilidade de reconhecimento do estrangeiro em si mesmo e no outro.

\section{O psicanalista fora de casa}

Esse foi o título de uma das mesas do congresso brasileiro realizado em Belo Horizonte (2019). Na largada da discussão, Oswaldo Ferreira Leite lança uma pergunta: "Haveria algum sentido em o psicanalista permanecer dentro de casa?"

Acreditamos ser o "fora de casa", nesse constante movimento de reinventar a psicanálise, um caminho que sempre enriquece a formação de novos analistas, na sua prática e reflexão clinico-teóricas.

Como nos disse Izildinha Baptista Nogueira40: “a psicanálise não segrega”. Dessa forma, cabe a nós o compromisso de investigar as marcas na subjetividade do abismo social em que vivemos, pois a clínica ao se deixar impregnar da história de uma sociedade nos acessa às marcas inconscientes.

\footnotetext{
39 Vetorazzo, H.(2013). Por uma psicanálise viva. Comissão de Publicação Departamento Formação em Psicanálise, organização. São Paulo: Primaveral Editorial. p.75.

4o Reunião científica promovida pela Diretoria científica da SBPSP, data 29/5/2019.
} 


\section{Ações institucionais}

Inspirados nos diversos autores e no diálogo construído, no decorrer de todos esses anos, o desejo de mundo foi levando a diretoria de atendimento à comunidade (DAC) da SBPSP a colocar o pensamento em ação, a se deixar penetrar pelas questões da cidade e a se relacionar diretamente com territórios diversificados.

O programa desenvolvido integra o projeto Psicanálise e suas Clínicas da atual gestão da SBPSP, coordenada por Bernardo Tanis ${ }^{41}$.

Uma das frentes da DAC tem dirigido o seu trabalho aos agentes multiplicadores de diversos setores da cidade. A intensa sobrecarga emocional e o grande sofrimento psíquico dos trabalhadores, que estão em contato direto com situações de vida muito precárias, têm sido a principal demanda das instituições. Por meio de grupos de reflexão, a equipe tem condições de fazer circular a palavra e ser acolhida em suas angústias. Os efeitos produzidos por essa escuta acabam por se propagar, também, à população assistida por tais profissionais.

No decorrer desses anos, temos acompanhado as seguintes ações institucionais no Setor de Parcerias e Convênios, coordenado por Silvia Bracco: 1. Guarda Civil Metropolitana da cidade de São Paulo; 2. Instituto Anchieta Grajaú; 3. Centro Estadual de Educação Tecnológica Paula Souza ETECS e FATECS; 4.Tribunal de Justiça/SP e CEVAT (Centro de Visitação Assistida); 5. Lar das Crianças (CIP); 6- UNAS - União de Núcleo e Associação de Moradores de Heliópolis e região; 7. Defensoria Pública do Estado de São Paulo - Santos/SP; 8- Grupo: Hora da conversa: EJA - educação de jovens e adultos e Cursos Técnicos do colégio Santa Cruz - S. Paulo; 9-Instituto Criar de TV, Cinema e Novas Mídias; 10-ASA -Associação Santo Agostinho.

\section{Colchão para o revêrie}

Entre as várias experiências surpreendentes que as pessoas que atendem a população vulnerável têm que viver, elegi, para exemplificar, uma cena da

${ }^{41}$ Tanis, B. http://www.bivipsi.org/wp-content/uploads/por-2018_94-104.pdf Conferência apresentada no I Simpósio Bienal da Sociedade Brasileira de Psicanálise de São Paulo (SBPSP), Psicanálise em Movimento, agosto 2018. 
parceria com a UNAS, do Centro de Criança e Adolescentes da região, descrita pelos colegas Eliana Caligiuri e Luiz Moreno Guimarães Reino:

Uma gestora que, diante de uma aluna doente, se vê aflita para levá-la ao médico. Quando fala que iria conversar com a mãe, a filha responde "minha mãe está na cama, fica no sofá, ela é drogada”. A gestora insiste sobre a necessidade da autorização, e vai à casa da criança para dizer que ela está precisando de cuidados, pedindo sua licença para conduzi-la ao médico. Feito o pedido, volta no dia seguinte e encontra a mãe de banho tomado, arrumada para irem juntas cuidar da filha. Para a menina, abre-se um novo cenário.

A gestora reconhece o lugar da mãe, que não pode ocupar o seu papel, apenas mostra a necessidade dos cuidados, sem sermão. Sustenta a própria impotência e a do outro e, dessa forma, como um dos melhores exemplos de ato analítico, toca a mãe a tal ponto que posteriormente esta aceita se submeter a um tratamento num serviço de saúde mental da cidade.

Os psicanalistas no grupo apontam a capacidade da profissional, a força do seu ato, que ao suspender o juízo e respeitar o lugar da mãe, abre o caminho para se concentrar naquilo que tinha que ser feito: tratar da criança e, por sua vez, quiçá pelos tortuosos caminhos da transferência, também alcançou a mãe. Mostraram o que já estava lá, sem forçar sentidos. É um momento de recuo da urgência do cotidiano, pois os educadores se sentem muito cansados emocionalmente, colados nas histórias das crianças, que também fazem lembrar as suas próprias realidades. Os educadores são pressionados diariamente a dar conta do abandono em que se encontra a comunidade em relação ao sistema de saúde, à proteção da lei, às organizações familiares. Para suportar paixões violentas ou mergulhar na biografia de pessoas silenciadas pela dor, além de plasticidade psíquica, os cuidadores exercitam uma espécie de atletismo afetivo. ${ }^{2}$

Como escreveu Nosek, nesse contexto, não seria o lugar para o psicanalista dar respostas terapêuticas: o central é não se vincular à ação. "Ele está preparado para fazer formulações diagnósticas. Não resolve equações, colabora para montálas. Sabemos que isso resulta por vias secundárias. Afinal, é mais difícil resolver uma equação ou encontrar constantes e o modo de construí-la? Ou seja, trata-se

\footnotetext{
$4^{2}$ Lancetti, A (2015). A contrafissura e a plasticidade psíquica. Hucitec.

A contrafissura é um sintoma social contemporâneo que opera na mídia, na política, na clínica - na subjetividade contemporânea. Plasticidade psíquica refere as mutações subjetivas dos cuidadores que protagonizam experiências promissoras e as transformações que ocorrem nos usuários da Rede de Atenção Psicossocial Brasileira.
} 
de encontrar trajetos expressivos e representativos para que a atividade do pensar evolua. Trata-se de sonhar." 43

Nesta mesma linha de destacar como o encontro do grupo abre espaço para a dimensão simbólica do acontecimento, concordamos com Marcelo Viñar que acredita que a nossa contribuição está, na medida do possível, em manter o conflito e mediar a descarga em ato. Sem seguir um caminho de desresponsabilizar o sujeito, mas diante dos acontecimentos violentos os protagonistas possam sustentar o conflito e manter suspensa a sanção punitiva imediata. "Essa suspensão criaria um 'colchão', um espaço de rêverie, ou melhor, espaços lúdicos nos espaços concretos, onde a catarse da violência humana poderia ser manejável, e onde a brutalidade poderia ser sancionada ou questionada e, deste modo, distendida."44

Uma das grandes potências da psicanálise é transformar uma conversa comum em um discurso metaforizado, sempre como guardiã da liberdade do sujeito na sua forma mais radical.

\section{Desejo de mundo}

O título dessa apresentação surgiu a partir da leitura do texto Uma clínica dos cuidados 45 , de Ana Cristina Cintra e Silvia Bracco, onde relatam sua experiência no Ateliê Acaia46: "As crianças que frequentavam o Acaia e outras instituições acabavam estigmatizadas como "meninos cheios de querer" e isso atrapalhava o bom andamento das atividades. Vitalidade, desejo de mundo vinham corromper a ordem estabelecida."

\section{Pandemia...}

O desejo de mundo parece ter sido abalado nesses tempos de pandemia. Com tal golpe de realidade, todos vivemos a interrupção de projetos, a forte quebra do cotidiano e com o prolongamento da crise disparam diversos tipos e

\footnotetext{
43 Pastore, J e Soares, S.(org) (2012). O psicanalista na comunidade. São Paulo.SBPSP. p. 100.

44 Viñar, M. (2000). Entrevista: Uma utopia sem lugar de chegada. Mal estar na atualidade. Percurso 25. Ano XIII.

45 Trabalho apresentado no Congresso da FEPAL, Lima, em 2018.

46 O Ateliê Acaia, desde fins de 1997 se ocupa da população que vive em duas favelas, do "Nove" e da "Linha", e num conjunto habitacional de baixa renda no entorno do Ceagesp, que é o grande centro de abastecimento de frutas e verduras de São Paulo. São famílias vivendo em condições de alta vulnerabilidade social, pouco estruturadas, onde $60 \%$ das crianças tem pais, irmãos ou parentes próximos no sistema prisional ou ligados ao tráfico de drogas. Durante 18 anos ofereceram oficinas apenas no contraturno escolar e no início de 2017 começaram a funcionar como escola.
} 
camadas de angústias. E, nas realidades latino-americanas, agudiza, ainda mais, o abismo socioeconômico.

Os vários movimentos das instituições psicanalíticas diante das emergências provocadas pela Covid-19, mostraram a criação de instrumentos ágeis e novos a uma demanda atípica, o que nos leva a repensar sobre uma série de modalidades da clínica psicanalítica.

Em São Paulo organizamos a REDE SBPSP, oferecendo conversas gratuitas e pontuais à população em geral e aos profissionais de saúde. Tem sido uma experiência que exige uma genuína disponibilidade, de abertura para construir significados. A construção desse programa e seu andamento merecem uma reflexão à parte.

No campo das parcerias, a maioria das instituições solicitou a continuidade das reuniões, via as plataformas online, explicitando a grande necessidade de manter o espaço para pensar sobre esse momento de medo e incertezas. $\mathrm{Na}$ situação de isolamento, a ameaça de diluição das subjetividades e grupos mobilizou o desejo de reencontrar o lugar, ali onde o grupo havia se fortalecido, e retomar as conversas de conflitos inusitados dos tempos atuais.

\section{Narrativa: recriando mundos}

Somos convocados a transitar em diferentes settings, tanto na clínica particular quanto no trabalho clínico em territórios expandidos, tornando-se muito atual a observação de Melanie Farkas, ao escrever que: "são situações e meios que extrapolam a condição ideal de privacidade e neutralidade da sessão de análise, no entanto, não impedem o profissional de psicanálise usar com proveito a regra de ouro da associação livre e da atenção flutuante para contribuir na reconstrução de enredos." 47

$\mathrm{O}$ ato analítico permanece com sua potência ao resgatar, por meio da narrativa, as redes associativas pelo trabalho onírico da vigília.

É nessa direção que Michèle Petit recupera a ligação entre narração e crise: "Muitos contadores de histórias ou mediadores de leitura de hoje em dia redescobrem essa antiquíssima observação quando trabalham com pessoas que viveram uma guerra, uma catástrofe, um trauma: o que está dentro deles deve

47 Pastore, J e Soares, S.(org.) (2012). O psicanalista na comunidade. São Paulo. SBPSP. p. 50 
primeiro encontrar uma voz do lado de fora por caminhos estéticos indiretos, para que porções inteiras daquilo que viveram não permaneçam entranhadas nas zonas mortas de seu ser. Para que possam testemunhá-los.”48

O espaço da psicanálise sempre foi encontrado nos interstícios, nas fendas do muro, e ao devolver a força poética à palavra, o sujeito tem a chance de encontrar novas formas para enfrentar o mundo.

${ }^{48}$ Petit, M. (2019). Ler o mundo: experiências de transmissão cultural nos dias de hoje. São Paulo. Editora 34. p.94 